\title{
Delivering a Forensic Expert Testimony for the Defense : Relevance, Hesitations and Reservations amongst Professionals in Sri Lanka.
}

This article attempts to examine the existing medico legal structure and practice in Sri Lanka with a view to identify a) the space and opportunity available for a forensic expert to appear as an expert witness for the defense in a criminal court b) the challenges and obstacles such experts would have to face in appearing for the defense. This submission, in essence, illustrates the relevance of defense expert evidence in Criminal Jurisprudence and elucidates the challenges exist in the Sri Lankan Medico-Legal Framework. Towards the later part of this paper, several foreign cases are used to demonstrate the need and the bearing of defense testimony in criminal trials.

Although the term ñ forensic expertò is used for the purposes of this article to denote all such experts as identified as áxpert witnesses ón accordance to the evidence ordinance of Sri Lanka, special reference has been made to the medical expert and expert scientific witness . Expert forensic witnesses can and are attending civil courts in matters connected to civil disputes, but, this article limits and focuses the discussion for criminal court room appearances.

Law concerning an ñexpert witnessò is clear in Sri Lanka. The term is defined in the section 45 of the evidence ordinance. The law does not define expert witnesses for the prosecution and defense separately. The Sri Lankan law introduces the ñconceptò of expert witness, and, depending on the perceived needs and pertinence of the court, the court may summon an expert either for the defense or for prosecution. However it is apparent that the appearances of expert witnesses for defense are very limited and scarce in Sri Lanka. In contrast, in developed countries almost all criminal trials have a defense forensic expert. Having a defense expert witness for both sides provides a unique platform with apparent balance of not only power, but intellectual-scientific commitment and bias in the court room. Therefore it is important to examine the situation in Sri Lanka and identify determinants for avoidance or hesitations for defense testimony by forensic experts in Sri Lanka.
The general practice in Sri Lanka involving medical/scientific ïlegal issues are that they are directed to a judicial medical officer by police (live cases) or coroner / magistrate (concerning a sudden / unnatural death). Cases of suspected murder, rape, assault are common examples. Other productions or biological samples collected from a scene of a crime are usually directed to the Government analyst for an opinion. As a result both the forensic medical officer and the Government Analyst send their reports to courts / relevant legal offices for administration of justice. When/If the trial comes up, the forensic experts who submitted reports are usually summoned by the state / prosecution for evidence. In the general practice of forensic medicine or science there is no involvement of a defense: nor defense attorney, nor defense scientific officer. It is ironically presumed that the state officers are handling such evidence so diligently and so perfectly. It is also ironically presumed that there would be absolutely no bias or no doubt about integrity or honesty of the government officers in handling medico-legal work. It is presumed that the state could prosecute, state could investigate, state could perform scientific tests, with no defense involvement prior to trial. However there is yet a tiny conflict with the traditional legal philosophical norms of natural justice here. The common suspect, in court has to defense himself with the hard earned nickels and dimes, challenging all these ñstate powerò This tradition, being long existed, many scientific experts are either oblivious or un engrossed to learn another better way of ñdoing thingsò.

There are several pertinent issues that needs discussion concerning the above predicament scenario. According to the law, the state prosecutes against crime charges, the Attorney General Department, a state agency is handling this with the assistance of the police. The police, a state agency is investigating the crime. The Judicial medical officer and the government Analyst, both state employees manage investigations and sending reports. The judicial medical officer and the analyst works as a member of a team along with the police in investigating and visiting the scene. At the end of investigations, 
an indictment is filed and the State counsel calls the forensic expert to courts in his witness list. The forensic expert usually visits the state counselôs chambers before the trial and at times exchange documents and a friendly smiles. The lay accused observes all these movements and interactions. In his mind a reasonable doubt, a negative opinion could develop concerning the integrity and biasness of forensic experts summoned by the state. The accused observes from the dock that all witnesses summoned by the prosecution had been against the accused. How could he assert only the scientific witness otherwise?

Justice studies unanimously endorse the notion that $\tilde{n}$ justice must not only be done, it must be seen to being done.ò In the minds of the lay accused, whether this presumption adheres, is a question? Do we consider this an important idea or do we have other more important things to attend?

The law seem to endorse a great trust in the state. The law assumes that the state is honest, prudent, integral, just, rational and unbiased. The state is an ideological entity but in practice, the state are the people: functions of the officers of the state. Could the officers of the state act/behave to the expectations of the law to such level of honesty and integrity. Are they different from the accused who is supposed to have been dishonest? Is it because of the state office? In other words, if the accused also held a state office, would he be honest and would not break law? Then, why are many state officers being indicted and punished for dishonesty and crimes?

One may argue why not the accused not retain a top lawyer? How could this be possible: crimes are usually associated with poverty!.

The relevance of a defense expert witness is numerous. It not only builds psychological esteem in the lay mind of the suspect, but also proposes an alternate insight to the case. It can also highlight technical and scientific insufficiencies and pit falls of the primary expert. The defense expert can also bring forth new evidence from the primary source of evidence presented in court. The defense expert can provide a scientific or rather technical defense for the accused based on sound scientific evidence, it can also demonstrate alternate or accepted but viewpoints different from prosecution witness . The defense expert with the help of the defense lawyer could create a valid doubt, also provide sufficient scientific evidence if available to discredit the prosecution expert witness. Thus, the court room enlightens with academia and wisdom. Balancing all presented facts and opinions, then it is up to the court and the jury to decide which position is the most appropriate, given the specific context. In this approach, justice is not only being done: it is seen to be done. Unfortunately most of the time, the opinion and the position of the expert witness summoned by the prosecution is accepted without any challenge!.

There is absolutely no barrier in the law for calling a defense expert witness. However, this costs money. The defense experts have to be paid for their services and travelling. On the other hand there are logistical and administrative barriers for a government officer to appear for defense and charge a fee. However retired experts do not have such an obstacle.

There are many experts who are willing to provide an expert evidence for the defense. However in practice not many engage due to several sociocultural and other reasons. One reason is that the expert who appear for the defense is culturally belittled by other collogues as ñmoney minded etcò. The ironic fact is that the prosecution expert witness also appear for a fee in the form of a government approved rates, although it is minimal, including a traveling fee etc. Also for postmortem examinations, there is a payment on top of the government salary.

As the existing practice has been going on for some generations, appearing for defense is not accepted by peers who follow the traditional professional culture. Second reason is that all forensic experts in Sri Lanka are known to each other well. Giving an opinion against another can create foe. A defense opinion can become a personal threat. One would not want to make an ñenemyò in the name of justice!. The third reason is that a lot of experts in Sri Lanka are administratively subordinate to others as for hierarchy, although educationally equal. In this set up, no expert would want to provide an opinion against one of their teachers or administratively higher senior colleague and get their career ruined. Training, imbibing and berth under one roof allow stagnating similar attitudes, discarding alternate and differential views. On the other hand, the lawyers and judges arenâ familiar with forensic scientific content, therefore, the court do not go in to deeper scientific analysis of the case. They rather depend on ordinary witnesses or other legal techniques to acquit or to convict. This is an unfortunate situation in Sri Lanka. 
In many situations in Sri Lanka it is observed that the expert witness attempts to be or almost act as an ñeye witnessò. They tend to makes very strong opinions and positions as if he was at the vicinity of the incident and observed the entire event. It illustrates that such experts deny any other possibility other than theirs. Experts must realize that they provide facts and opinions to courts based on what they examined subsequent to the event concerned, and therefore what exactly happened could be distant to the opinion possessed.

Although it is accepted that it is the responsibility of the defense lawyer to elucidate a defense from the existing expert, there are practical reasons why he cannot. Is it fair to consider the expert summoned by the state to call the ñexpert for the courtò including for the defense? The expert summoned by the prosecution engaged in the investigations with the police, usually have discussions with the state attorney about the case prior to the hearing. They hear histories, stories of victims through victims family. The forensic expert working with the police can develop a ñconvictingò mentality. In this context, is it possible to have a totally unbiased opinion?

The flip side is that in the absence of defense experts, the opinion of the expert presented prevails. Practicing in a geographical region for a long time, association with the police, state attorneys and judges etc., predispose an expert witness to develop an unwarranted ñpowerò in the court house that results in adamant and strong opinions. Although the court could dismiss an opinion of an expert theoretically, in practice, it is highly unlikely in the absence of a second opinion. Such developments are seen as negative attributes which could be negated with the use of suitable defense expert in the name of justice. The other central issue having one expert opinion is that it could only demonstrate one side of the science to a non- scientific court room. This opinion can be pre-decided or non evidence based: could even be an assertion. There is no practice of a verification of the photos, slides etc., shown by the expert witness, in Sri Lanka. They are presumed to be very honest and integral. Eventually, everything comes down to the personal integrity of the expert: Why should the suspect or the court trust the expert witness, amidst all sorts of allegations and corruption charges against many government officials? Could the scientific expert be different because he is trained in science?

Although there are no legal restrictions, in routine practice, a defense medical officer or a defense scientist are not allowed in a post mortem examination or in a clinical examination generally. There had been instances where such defense expertsô presence were allowed but those were VIP cases. To the commoner, those approaches are not possible. If there is a defense expert on behalf of the accused present in all scientific examinations, he could document the entire procedure and ensure that justice to the accused is protected.

The government analyst is the sole authority on certain aspects of forensics in our country. In this context how a defense expert could be made available? Will a defense expert be allowed to observe proceedings in the government analyst department? Would such an approach generate a chaos? What type of chaos? How do you ensure all standards and protocols are followed in state labs which are on budget restrictions? Is examining documents produced alone enough in this respect? What could be the most appropriate way? What are the ways other countries do such functions?

In Sri Lankan set up, forensic toxicologists could only exist in the Government analyst department, no other units are recognized by law as service units for forensic toxicology. These barriers have resulted forensic toxicologists well trained who used to work in other units to leave the country and lead fully fledged forensic toxicology labs in foreign university setups. Same applies to finger and palm print analysis and document analysis. Unless these restrictions are reformed no parallel development of these sciences could be envisaged.

Many believe that the Sri Lankan police is not sufficiently trained to handle a serious forensic case. So are the inquires in to sudden deaths. Many serious crimes are dismissed in courts due to mishandling of evidence, and mal procedures. How could these impact the expert testimony of the scientific witness?

It must be mentioned that in many countries, number of exonerations are done, based on defense expert testimony. Many accused are acquitted merely on the basis of the defense experts evidence and illustrations. Also, it must be mentioned that unscientific evidence and stubborn opinions provided in the past have incarcerated innocent people in many countries, many years after. Those suspects are exonerated using defense expert testimony. When will such a move appear in Sri Lanka? 
There is very little or no evidence concerning action on perjury by expert witnesses in Sri Lanka. There are no means to make checks and balances of the practice and evidence of an expert witness. In short there is no quality assurance mechanism for expert testimony in Sri Lanka.

If there is a defense expert available, at least then there is arguably a balance of scientific power that could minimize bias, prejudice, adamancy, dishonesty of the expert testimony which in turn will illuminate justice.

It is high time that a team of forensic scientists come forward in Sri Lanka for providing defense opinions, for the interests of justice. This not only improves quality of expert testimony and justice administration in the country but also facilitates advancement of forensic sciences.

Dr. Induwara Goonerathne Editor

Sri Lanka Journal of Forensic Medicine, Science and Law

\&

Senior Lecturer

Department of Forensic Medicine

Faculty of Medicine

University of Peradeniya, Sri Lanka. 